\title{
Development of Smart Planetary Wheel Chair for Rural Area
}

\author{
Suraj Kumar Vishwakarma \\ Department of Mechanical Engineering \\ DIT University, Dehradun, Uttrakhand, India \\ Nitin Kumar Gupta \\ Department of Mechanical Engineering \\ DIT University, Dehradun, Uttrakhand, India \\ Ramesh Kumar \\ Department of Electronic and Communication Engineering \\ DIT University, Dehradun, Uttrakhand, India
}

\begin{abstract}
Life of disable people is very arduous especially while moving from one place to another in rural area. In general all the wheel chairs are available in the market are designed and fabricated for smooth surface, but $\mathbf{7 5 \%}$ of people with disabilities live in the rural area where uneven surface are common. The present work demeanor with the development of smart planetary wheel chair for rural area. The use of planetary wheel reduces the impact due to uneven surface and inclined plane. The model of the smart planetary wheel chair are designed and simulated in the CREO 3.0 and ANSYS 14.0. The imitative model of wheel chair is validated under actual loading condition.
\end{abstract}

Keywords- Demeanor, Design and imitative, Disable person, Impact, Inclined plane, Smart planetary wheel chair, Uneven surface.

\section{INTRODUCTION}

Differentiable people are facing very much snag while navigating for day to day work. They get tired and feel clumsy. To overcome this problem, many researchers have developed smart wheel chair, so the disable people can travel without the help of any person, and also facilitate them to walk long distances. Most of the people reckon difficulty to draw or drag object while they are moving on uneven surface and inclined plane. Some of the wheel chair are very much sumptuous and made for smooth surface. And it's very difficult to everyone to purchase it. For that intention, this paper aims to develop a smart planetary wheel chair for rural area. So that maximum people belonging to rural and villages can use it. It is expectation that this new design will improve effective mobility. The models of planetary wheel chair are designed on CREO 3.0 and stress analysis of essential components is done using commercially available ANSYS 14.0. After the design of planetary wheel chair, the fabrication is done by the proper selection of material, which shows that the wheel chair is very emphatic for mobility.

\section{RESEARCH METHODOLOGY}

A. Framework

Model of the frame prepared is shown in Fig.1, which is pinchbeck in CREO 3.0 and ANSYS 14.0. This software assent us to design, draft and simulate the actinic of the model of the rightful load application over it. Frame constituted of mild steel (AISI 1018). The physical properties of the material are given [10].

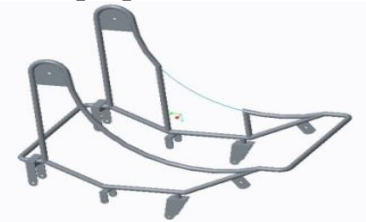

Figure 1. Isometric view of the frame (Design in CREO) 


\section{B. Framework of Planetary Wheel}

It is observed that all the wheel chair are entity developed for the smooth surfaces and it is also observed that impact acting on the frame of wheel is very low, but when wheel chair is to move at uneven surfaces and on a inclined plane, then impact acting on the frame of wheel is more, due to this reason we have designed a planetary wheel chair which is shown in Fig 2. Dimensions of the planetary wheel chair are given in table No.1.

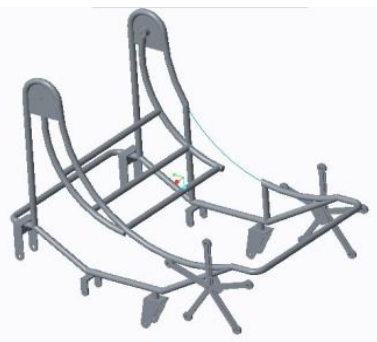

Figure 2. Isometric view of frame with planetary wheel chair

\begin{tabular}{|c|c|} 
Table No-1 Dimension of Smart Planetary Wheel Chair \\
\begin{tabular}{|c|c|}
\hline Dimensions & Value (cm) \\
\hline Length of the platform & $\mathbf{1 5 8}$ \\
\hline Width of the platform & $\mathbf{7 2}$ \\
\hline Height of the platform & $\mathbf{1 2 6}$ \\
\hline
\end{tabular}
\end{tabular}

\section{Design Analysis and Simulation}

At present day software is very essential for design and analysis. By the using of software (CAD, CAAD, CREO, SOLIDWORK, ANSYS etc) researcher designed a different type of model, assemble the different sections, determine the maximum stress condition at any section of the model etc. In this paper design is done with the help of software (CREO 3.0 and ANSYS 14.0) and also determines the maximum stress acting on the frame and check the FOS (factor of safety) of the planetary wheel at static condition. After this we found that our design is safe at uneven surface and inclined plane [10].

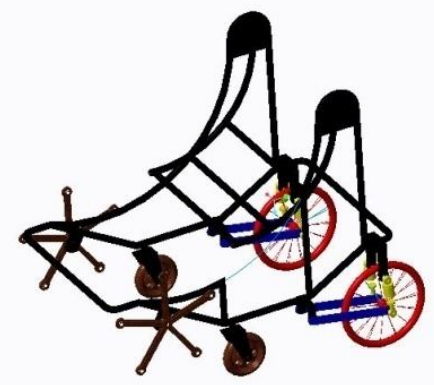

Figure 3. Final isometric view of the frame with planetary wheel chair

When the vehicle hits an obstruction due to uneven surface and inclined plane, impact force is transmitted to chassis through suspension spring. So, the component on which suspension spring is mounted is the critical component [10]. The shape of wheel chair is complicated; due to this we applied FEM (finite element method) to calculate the maximum yield stress at static condition and FOS (factor of safety). It is calculated by ANSYS 14.0 and property of material.

\section{ELECTRICAL AND ELECTRONIC COMPONENTS DESCRIPTION}

\section{A. Accelerometer}

Accelerometer is inputs of this project. The Accelerometer sensors are knitted on headphone and them transducer change in acceleration of head movement to voltage signal which is sent to ADC input of microcontroller. 


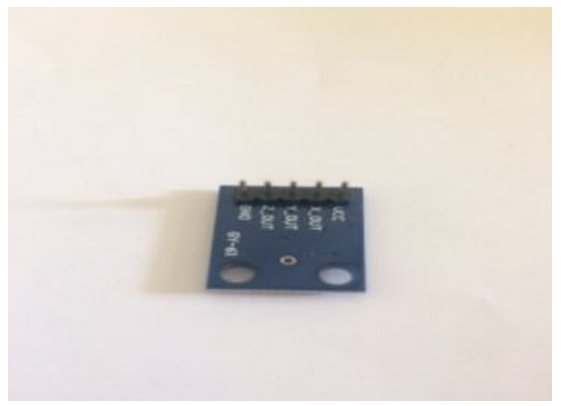

Figure 4. Accelerometer

B. Joystick

Joystick is one of the main inputs for this project. The outputs of the two variable resistor of the joystick are connected with the two channels of ADC.

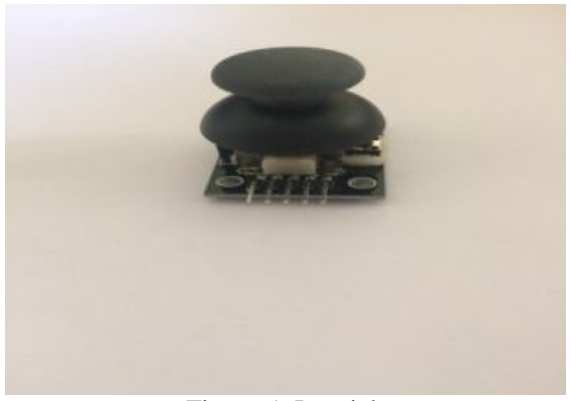

Figure 5. Joystick

C. Speech Synthesizer

Speech synthesizer is inputs for this project. Speech synthesizer module works by endowment user input voice command and send signal to actuators.

D. Ultrasonic Ranging Module

It is used to detect the obstacle. It is used to halt the wheelchair.

E. Position Switches

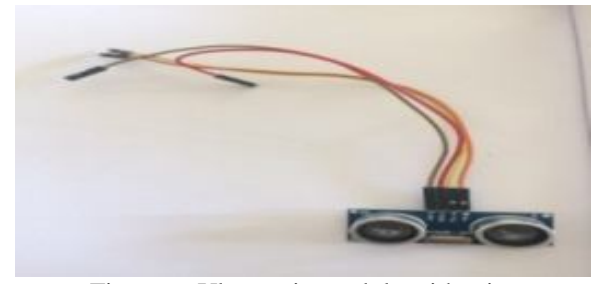

Figure 6. Ultrasonic module with wire

These switches are indulgent at chair, to switch the input control unit as Speech or Joystick. 


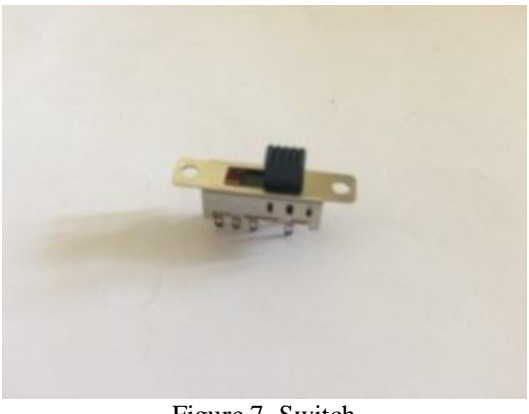

Figure 7. Switch

\section{F. Microcontroller}

It is the main computational and processing part of the smart planetary wheel chair that takes input from the sensor, processes it and gives output. It operates at high frequency of $12 \mathrm{MHz}$ and acts as control center for the robot.

G. Relay Switch

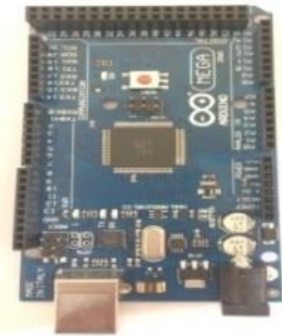

Figure 8. Microcontroller

A. relay is an electrically operated switch. Many relays use the electromagnet to operate a switching mechanism mechanically. It is used to switch on or off electrical circuits operating at high voltage using a low DC control voltage. Relays are used to provide high voltage to motors. The switching of relay is execution using 1293D motor driver.

H. Motor Drivers

Motor drivers amplify the TTL output of the microcontroller such that it can drive the respective actuators. L293D IC is used for switching the relay driver. It is dual H-Bridge IC.

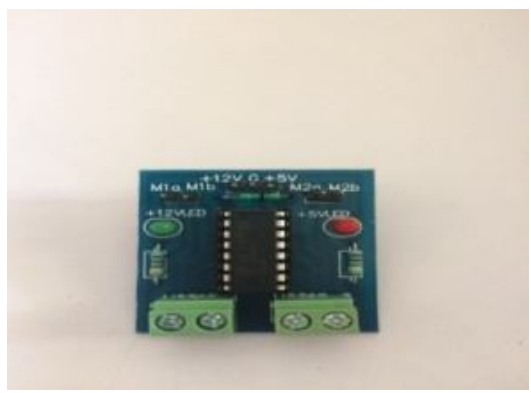

Figure 9. L293D IC Module

\section{Liquid Crystal Display}

LCD is the visual display unit of the project. It is used to display the values of asunder interfacing input.

J. Actuators

Actuators are the motors that drive planetary Smart Chair 
K. Motor Selection

The $\operatorname{rpm}$ of the motor $(\mathrm{N})=40 \mathrm{rpm}$, Diameter of main wheel $=0.48 \mathrm{~m}$

$$
\begin{aligned}
\text { Now, speed of motor } & =3.141 \times \mathrm{D} \times \mathrm{N}(\mathrm{m} / \mathrm{min}) \\
& =3.141 \times 0.48 \times 40(\mathrm{~m} / \mathrm{min}) \\
& =60.3072 / 60 \\
& =1.005(\mathrm{~m} / \mathrm{sec})
\end{aligned}
$$

If we assume that wheel chair takes 2 seconds for accelerating form 0 to $1.005 \mathrm{~m} / \mathrm{sec}$, then

$$
\text { Acceleration }(\mathrm{a})=\mathrm{V} / \mathrm{t}=1.005 / 2=0.5025 \mathrm{~m} / \mathrm{sec}^{2}
$$

Now, the total weight of the frame wheel chair $(70 \mathrm{~kg})$, person $(80-90 \mathrm{~kg})$, battery $(10 \mathrm{~kg})$ and motor $(3-4 \mathrm{~kg})$

$$
\begin{gathered}
(\mathrm{M})=180 \mathrm{~kg} \text { (Maximum weight condition) } \\
\text { Required force }=\mathrm{M} \times \mathrm{a} \\
=90.49 \text { Newton }
\end{gathered}
$$

Now, to get a force of 90.49 Newton on outer diameter of wheel we required Torque,

$$
\begin{gathered}
\text { Torque }=\text { force } \times \mathrm{r}(\text { radius of main wheel }=0.24 \mathrm{~m}) \\
=21.84 \mathrm{Nm}(\text { On the axis }) \\
\text { Angular speed }=2 \times 3.141 \times \mathrm{N} / 60 \mathrm{~d} \\
=4.188 \mathrm{rad} / \mathrm{sec}
\end{gathered}
$$

Moto Power $=$ Torque $\times$ Angular speed

$$
=91.416 \mathrm{Watt}
$$

Taking into condensation fraction etc, 120-140 watt I think to suitable

\section{Selected Motor Specifications}

$\begin{array}{ll}\text { Type } & : \text { - D.C. geared motor } \\ \text { Required Power Supply } & :-12 \text { Volt and } 16 \text { ampere current } \\ \text { Speed } & : 40 \mathrm{RPM} \\ \text { Average torque } & :-21.84 \mathrm{Nm} \\ \text { Average power } & :-120-140 \mathrm{Watt}\end{array}$

\section{FABRICATION OF ACTUAL MODULE}

After the designed on cero model is fabricated in workshop to test the validity of design and also performed the analysis. Which show that, the new innovative planetary wheel chair can be very reliable and useful for the rural area within the low cost. 


\section{International Journal of Innovations in Engineering and Technology (IJIET) http://dx.doi.org/10.21172/ijiet.83.017}

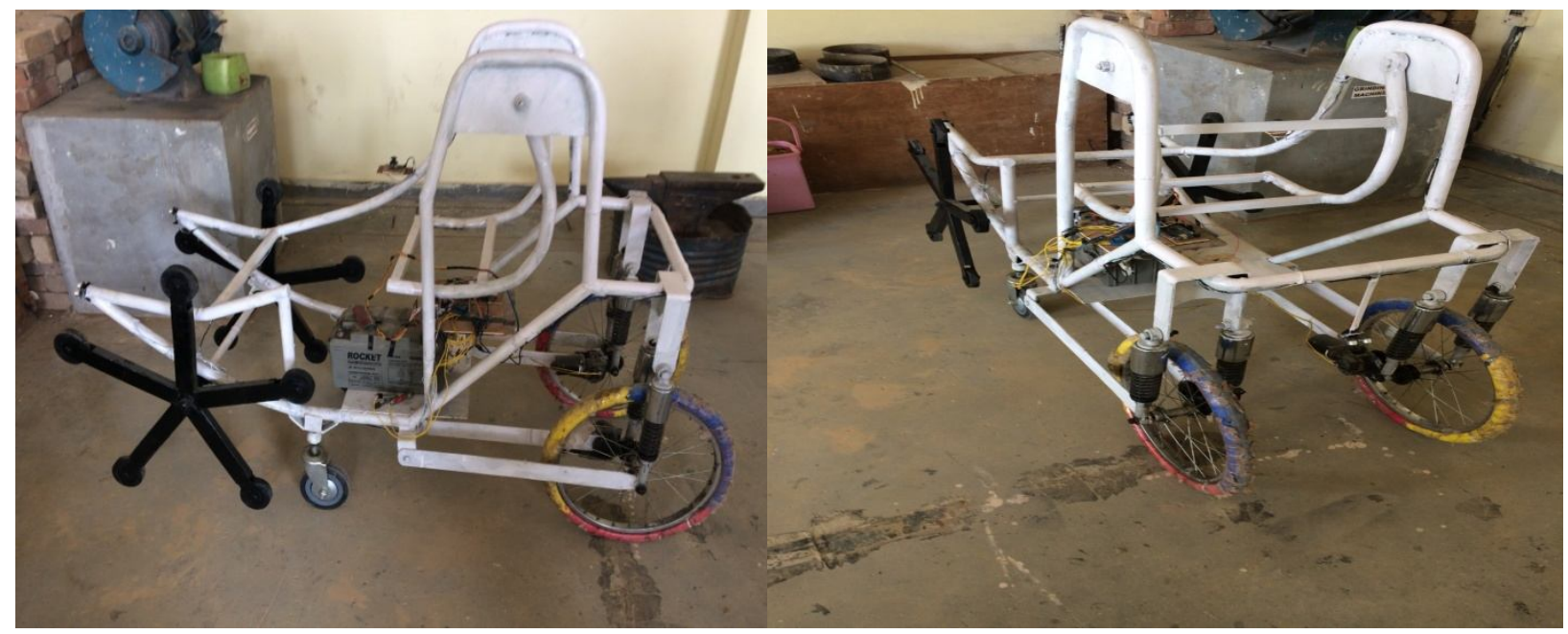

Figure 10. Side view and isometric view of planetary wheel chair

\section{RESULTS AND CONCLUSION}

An attempt has been made to develop of smart planetary wheel chair for rural area. The designed and fabricated prototype will be more effective in providing mobility for disabled people in the rural areas. By improving system, we directly enhance the life style of the disabled person in the rural area. This paper is more useful for elders, patients and physically challenged people those live in the rural area. Hope that this kind of system could contribute to the evolution of the wheelchair technology.

\section{REFERENCES}

[1] Ajit A. Mohekar, Savita V. Kendre,Tanmay N. Shah, Prof. P. D. Sonawane, Prof. Dr. S. T. Chavan"design of an innovative retrofitted tricycle for a desiable person "International journal of advance research in science and engineering"' volume no.4, issue 07,july 2015.

[2] Vivek Kaundal, Rajesh Singh, Anant Wadhwa,Shashank Mishra,Aadhar Rastogi, "Low Cost Robotic Wheel Chair for Disabled People in Developing Countries" Conference on Advances in Communication and Control Systems 2013 (CAC2S 2013).

[3] Rashid Ahmed K., Safar Abdul Razack, Shamil Salam, Vishnu Prasad K.V.,Vishnu C. R. " Design and Fabrication of Pneumatically Powered Wheel Chair-Stretcher Device', International journal of innovation research in science, engineering and technolog,vol.4,issue 10, October 2015.

[4] K.Kalaiyarasu,G.Leelavathi, M. Suganya, S. Vignesh, N. Santhosh, "Design and Implementation of Smart Roulettle using Gesture Control'’JSART - Volume 2 Issue 3 -march 2016.

[5] G Azam and M T Islam, "Design and Fabrication of a Voice Controlled Wheelchair for Physically Disabled People", Corresponding author: tazul2003@yahoo.com.

[6] Brigida Monica Faria, Luis Miguel Ferreira, Luis Paulo Reis, Nuno Lau, Marcelo Petry, and Joao Couto Soares, " Manual Control for Driving an Intelligent Wheelchair: A Comparative Study of Joystick Mapping Methods"'.

[7] Parris Wellman, Venkat Krovi, Vijay Kumar, and William Harwin, "Design of a Wheelchair with Legs for People with Motor Disabilities", IEEE transaction on Rehabilitation Engineering, VOL. 3, NO. 4, 121 ecember 1995.

[8] Arun Manohar Gurram, P.S.V Ramana Rao, Raghuveer Dontikurti, "Solar Powered Wheel Chair: Mobility For Physically Challenged", International Journal of Current Engineering and Technology, Vol.2, No.1, March 2012.

[9] Yogesh Mangaonkar, Prof. Ritesh Banapurkar, "Design and Fabrication of Self-Guided Smart Chair System for Library Book Access", IJESC 2016.

[10] Suraj Kumar Vishwakarma, Nitin Kumar Gupta," Design and Fabrication of an Innovative Planetary Wheel Chair for Ruler Area", IJSER2016. 